\title{
REFLEXÕES SOBRE UM GRAMSCI REGIONALISTA, INOVADOR E BRASILEIRO, DO PASSADO E DO PRESENTE
}

Ivan Márcio Gitahy Junior

Doutorando em Ciências Sociais. Mestre em Educação. Docente do curso de Admininistração e Gestão Comercial da Universidade do Oeste Paulista e Coordenador da pós graduação do SENAC. E-mail: ivan.mjunior@sp.senac.br

\section{RESUMO}

O presente estudo tem por objetivo analisar teoricamente os pensamentos do filósofo italiano Antônio Gramsci bem como os desafios enfrentados, especificamente nos assuntos relativos à hegemonia, democracia, marxismo, lutas de classes, proletariado, a rearticulação de lutas sociais e o empobrecimento intelectual da Europa, evidenciando como os seus pensamentos ainda encontram-se presentes em nossa sociedade. A fim de atingir o objetivo realizou-se uma pesquisa bibliográfica e qualitativa. Diante da pesquisa pode-se afirmar que o homem não é naturalmente social, ele é historicamente social, podendo tornar-se um internacionalista, mas nunca deixando de ser um regionalista sendo considerado um construtor de nacionalidades lutando por seus direitos como por exemplo a luta entre a sociedade e as classes subalternas e tentando sempre entender conceitos e as relações que se estabelecem entre a classe e nação.

Palavras-chave: Hegemonia. Educação. Lutas sociais. Gramsci. Marxismo

\section{INTRODUÇÃO}

O presente trabalho torna-se relevante por buscar compreender em que medida os pensamentos de Gramsci ainda encontram-se presentes em nossa sociedade. Os objetivos fazemse presentes no momento em que se destacam seus pensamentos que de antigos tornam-se atuais, que fazem dele um autor contemporâneo e muito próximo de nossa realidade sócioeconômico-cultural.

No presente artigo fazem-se presentes as considerações acerca de Gramsci e seus pensamentos sobre seu regionalismo marcante, concepções e conceitos sobre hegemonia e sua relação com a libertação tratada também por Paulo Freire.

Outro ponto de destaque é a discussão do proletariado, da pequena burguesia e dos movimentos revolucionários em seu sentido marxista, considerando reflexões acerca do pensamento de um Gramsci inovador, levando em consideração pensamentos e relações que se estabelecem entre o Estado, a Igreja e os intelectuais.

Certa visão sobre o capitalismo moderno, americanismo e fordismo também faz parte desse estudo. A seguir tem lugar à filosofia da práxis e seus desdobramentos. Finalizando aparecem os pensamentos de um Gramsci "brasileiro" totalmente imerso na atualidade bem como na regionalidade, vindo então a conclusão. 


\section{1. $O$ pensamento de um Gramsci regionalista.}

Em meio a suas inúmeras reflexões, Gramsci, nunca deixou de pensar na Itália como uma nação forte, pode-se dizer que foi um regionalista fazendo da justiça e da igualdade alguns de seus princípios fundamentais, ainda que sem deixar de lado o pensamento sobre a importância de se ter um proletariado unido.

Um pensamento bem marcante e presente na personalidade do autor, o regionalismo, fica claro quando se percebe suas motivações políticas, sua preocupação com a humanidade, com o proletariado e com a civilização. A crença em um sistema político proletariado internacionalista e solidário veio com a Revolução Russa, mas a preocupação com uma Itália mais justa, onde houvesse espaço para a educação e melhores condições de vida à população, nunca cessou.

Gramsci foca, em um de seus estudos, as reflexões sobre a hegemonia e para se iniciar essa discussão é importante um questionamento sobre que espaço é necessário, à hegemonia, para que ela possa se estabelecer? E em que condições ela pode se estabelecer? Pode-se apreender que a hegemonia vem arraigada de relações sociais levando-se em conta o papel que tem o Estado e a sociedade neste contexto. Para discutir a hegemonia é importante pela visão de Del Roio (2009), que se mencione a relação entre estrutura e superestrutura, onde a estrutura enfatiza o papel do Estado e a superestrutura representa o pensamento apresentado no capitulo sobre Americanismo e fordismo nos Cadernos de Cárcere.

Desse pensamento pode se chegar à hegemonia, tratado por Gramsci (2002), como a combinação da força e do consenso, que se equilibram de modo variado, sem que a força suplante em muito o consenso, mas, ao contrário, tentando fazer com que a força pareça apoiada no consenso da maioria. Daí vem à necessidade de se tentar entender o que significam nação e classe e qual a relação que se pode estabelecer entre elas.

Para Coutinho (1999), as organizações populares tanto na sociedade civil como na política se multiplicaram e se diversificaram fazendo com que houvesse uma ruptura nas tentativas de construção da hegemonia popular. Para que se possa construir essa tal hegemonia, deve-se conquistar o poder do governo levando em consideração as experiências administrativas.

Não se pode mencionar hegemonia e libertação quando se quer abordar o papel decisivo na elaboração de uma práxis político-pedagógica original no Brasil, sem citarmos Paulo Freire juntamente com Gramsci. Como passar de grupos subalternos a grupos dirigentes, sem tentar identificar as fases que os levam a adquirir a autonomia diante dos inimigos e a adesão de grupos que auxiliam na conquista desta hegemonia na tentativa de unificar o Estado. 
Segundo Coutinho (1999), pode-se considerar a libertação e a hegemonia, como paradigmas fundamentais, pois as concepções que elas expressam continuam sendo atuais passíveis de desdobramentos de um processo político-pedagógico criativo que está longe de se esgotar. Pode-se mencionar que a união desses autores, Gramsci e Freire, é de fundamental importância para a educação e a filosofia política brasileira e latino-americana, onde ambos se complementam.

A libertação e a hegemonia, não podem ser confundidas, assim como Paulo Freire e Gramsci, ambos têm seu valor e suas peculiaridades. Freire, porque aprofunda mais os horizontes da libertação, da utopia, dos movimentos, da ética, da afetividade, do diálogo, da intersubjetividade, das relações pedagógicas, da pluralidade, da periferia e dos oprimidos; já Gramsci; enfatiza a estratégia política, o enfrentamento ideológico, a classe, a organização do partido, a dialética, a conquista da hegemonia, a formação de dirigentes, a criação do Estado democrático-popular.

A conquista da hegemonia advém do processo de libertação, devendo sempre se evitar ideias pequenas de política e de partido para que possa se tornar uma arma poderosa na superação da concepção de poder como dominação e entendê-lo como relação pedagógica entre pessoas livres e socializadas que rompem com o capitalismo e com alguns paradigmas, como: governante e governado, Norte e Sul, centro e periferia.

Segundo Coutinho (1999), não se pode afirmar que o controle dos aparatos repressivos do Estado reside no poder das classes dominantes sobre o proletariado, mas sim que este poder é garantido pela hegemonia cultural que as classes dominantes exercem sobre as dominadas, através do controle do sistema educacional, das instituições religiosas e dos meios de comunicação

Usando deste controle, as classes dominantes "educam" os dominados para que estes vivam em submissão às primeiras como algo natural e conveniente, inibindo assim sua potencialidade revolucionária. Assim, por exemplo, em nome da "nação" ou da "pátria", as classes dominantes criam no povo o sentimento de identificação com elas, de união sagrada com os exploradores, contra um inimigo exterior e a favor de um suposto "destino nacional" de uma sociedade concebida como um todo orgânico desprovido de antagonismos sociais objetivos. Assim se forma um "bloco hegemónico" que amalgama a todas as classes sociais em torno de um projecto burguês. O poder hegemônico combina e articula a coerção e o consenso. (Coutinho, 1999, p.320) 
Ainda para Coutinho (1999), a hegemonia é o conceito que permite compreender o desenrolar da história italiana e da Ressurreição, que se contasse com o apoio de massas populares, como os camponeses, a maior parte da população, poderia ter adquirido um carácter revolucionário.

Sendo assim, para Semanaro (2001), a hegemonia também pode ser entendida como o exercício das funções de direção intelectual e moral unida àquela do domínio do poder político. 0 proletariado urbano, rural e também a pequena burguesia, classes subalternas, não estão unidas e sua união ocorre somente quando se convertem em Estado, de outra maneira apenas desempenham uma função descontinua e desagregada na história da sociedade civil dos estados singulares.

Para Gramsci (2002), a crise da hegemonia se manifesta quando, ainda que mantendo o próprio domínio, as classes sociais politicamente dominantes não conseguem mais ser dirigentes de todas as classes sociais, isto é não conseguem resolver os problemas de toda a colectividade que impõem a toda a sociedade a própria concepção do mundo. Consegue-se indicar às classes sociais soluções concretas aos problemas deixados sem solução, tornando-se dirigente e, expandindo sua própria cosmovisão a outros estratos sociais, criando um novo bloco social, que se torna hegemônico, um momento revolucionário voltando-se inicialmente para o nível da superstrutura, isto é, político, cultural, ideal, moral.

\section{O pensamento de um Gramsci inovador.}

Pode-se entender que no pensamento de Gramsci, ainda jovem, não há uma dialética entre o sujeito e o objeto. O predomínio da subjetividade se faz presente quando se revela a aproximação dos operários com os estudantes iniciando um movimento político-social e cultural. Será que o mundo do capital deve estar apartado do mundo do trabalho?

Esse questionamento pode ser respondido, na medida em que se revê a posição das classes que estejam subordinadas a hegemonia do poder. Em 1919 há uma mobilização total da classe operária reconstituindo-se assim o movimento operário com o apogeu da Revolução socialista internacional. Os pensamentos de Gramsci inicialmente vierem de influências de Croce que por sua vez nascem de uma tentativa de se reconstruir o Marxismo. O afastamento entre eles, Gramsci e Croce, inicia-se em 1923, com o surgimento do facismo/bolshevismo.

Neste contexto, entende-se a relação entre o Estado, a igreja e os intelectuais tendo como objetivo principal a auto-educação, pois com isso, acontecem a re-educação dos operários 
voltando a se recomporem, em um processo de reorganização. Um deve aprender com o outro, havendo assim, a dialética entre educador e educando.

Em uma visão americanismo e fordismo, a classe operária deveria ser inibida e transformada, a partir das mudanças do processo produtivo, nesse contexto é fundamental que se faça uma análise sobre a atual conjuntura internacional. Há um deslocamento do dinamismo econômico da Europa para os Estados Unidos? Parece que os EUA estão na moda e a hegemonia começa a nascer das fábricas, ou seja, a hegemonia forte deve nascer da classe operária.

Em uma perspectiva mais atual, o proletariado deve ser a classe mais organizada e preparada, pois ela é um fenômeno histórico de autoconsciêntização e organização própria, como uma tentativa de contestar o poder dos EUA e tentar minimizar as desigualdades sócioeconômicas.

Uma das características dos EUA é o prevalecimento de intelectuais orgânicos, ou seja, aqueles que organizam a produção, não havendo um grande número de intelectuais tradicionais. $\mathrm{E}$ como criar um proletariado consciente se eles são tão diferentes, quer sejam como tipos humanos ou nacionalidades diversas? As classes subalternas que estão sendo disciplinas afetam as classes dominantes que estão em crise.

Hoje, em 2012, pode-se verificar que a classe operária parece estar efetivamente autônoma, mas está submetida à soberania burguesa e sua diversificação. Não se pode deixar de mencionar aqui a Revolução Passiva como um movimento de reação partindo da periferia referindo-se a uma pressão das classes subalternas incapazes de se organizarem em uma revolução e as classes dominantes se organizando para incorporarem algumas demandas associadas ao impacto interno, ou seja, a ação do capital tentando construir um novo trabalhador.

Gramsci (2002), afirma que sob o capitalismo moderno, a burguesia pode manter seu controle econômico permitindo que a esfera política satisfaça certas demandas dos sindicatos e dos partidos políticos de massas da sociedade civil. Assim, a burguesia leva a cabo uma revolução passiva, ao ir muito aquém dos seus interesses econômicos e permitindo que algumas formas de sua hegemonia se vejam alteradas. Gramsci dava em exemplos os movimentos como o reformismo e o fascismo, a administração científica e os métodos da linha de montagem de Taylor e Ford.

Ainda para Gramsci o partido revolucionário é a força que permitirá que a classe operária desenvolva intelectuais orgânicos e uma hegemonia alternativa dentro da sociedade civil. A natureza da complexidade da sociedade civil moderna implica em uma única tática capaz de minar 
a hegemonia da burguesia e chegar ao socialismo, na guerra de posições, A guerra em movimento levado a cabo pelos bolcheviques foi uma estratégia mais apropriada à sociedade civil, existente na Rússia Czarista.

Apesar dessa afirmação, a de que a fronteira entre as duas é nebulosa, Gramsci alerta contra a adoração ao Estado que resulta na identificação da sociedade política com a sociedade civil, como no caso dos jacobinos e os fascistas. Ele acredita que a tarefa histórica do proletariado é criar uma sociedade regulada e define a tendência do Estado a desaparecer com o pleno desenvolvimento da capacidade da sociedade civil para regular-se a si própria.

Gramsci chega o Marxismo com críticas ao Croce, iniciando assim, a expressão "filosofia da práxis", definido como um conjunto de atividades materiais e intelectuais que auxiliam na transformação da realidade. Neste contexto só é realidade aquilo que o homem conhece, ou seja, o homem só se apropria do que é real. A filosofia da práxis pode ser encarada como a mundanização do homem, onde o homem faz o mundo na medida em que se apropria dele.

Que lugar a política ocupa na filosofia da práxis? Como centro de uma grande preocupação, onde essa política deve ser o princípio de uma supra-estrutura.

Com o desenvolvimento deste pensamento, pode-se entender que a política, como ciência, está na totalidade social, já que a mesma surge do desenvolvimento da sociedade civil, onde essa, é o movimento de contradição, gerando elementos de complexidade.

Em um raciocínio dialético, pode-se dizer que a negação da política está presente em uma concepção economicista, na medida em que a revolução nega a política burguesa.

Mark \& Engels (1998), mencionam que a filosofia da práxis político-pedagógica representa um projeto de hegemonia que forma pessoas críticas, libertas e éticas, desencadeando um movimento real que deve superar o estado atual das coisas.

\section{O pensamento de um Gramsci "brasileiro".}

Deve-se a Gramsci grande parte das transformações ocorridas, no Brasil, com relação ao pensamento marxista, pensamento esse presente na política, nas ciências sociais e principalmente no serviço social

Simionatto (1995), tenta reconstruir as influências de Gramsci no debate político e universitário do Brasil mencionando a hegemonia, os intelectuais, o Estado ampliado e a filosofia da práxis, na medida em que tais categorias são fundamentais para a sociedade contemporânea. 
Não se pode deixar de mencionar o papel de Gramsci no serviço social, como suas ideias de marxista italiano, foram capazes de motivar respostas originais num terreno específico de produção acadêmica e da intervenção profissional. É imprescendível o entendimento sobre o pensamento social brasileiro bem como sua contribuição a respostas adequadas a problemas postos pela crise do mundo contemporâneo.

Outro ponto de fundamental importância é a contribuição de Gramsci no conceito de sociedade civil, no Brasil. No contexto da luta contra a ditadura, o termo sociedade civil tornou-se sinônimo de tudo aquilo que se contrapõe ao Estado ditatorial, e também por civil significar, no Brasil o contrário de militar.

Para Semararo (2001), Gramsci define sociedade civil como uma arena privilegiada de luta de classe, onde se trava uma intensa luta pela hegemonia e, precisamente por isso, ela não é o outro do Estado, mas sim a sociedade política.

Enquanto Marx e Engels teriam se fixado nas relações econômicas

....a sociedade civil que Gramsci tem em mente quando se refere a Hegel não é a do momento inicial no qual explodem as contradições que o Estado terá de dominar, mas a do momento final em que, por meio da organização e da regulamentação dos diversos interesses (as corporações), são fixadas as bases para a passagem do Estado (Bobbio, 1999, p.57)

Neste contexto, para Bobbio (1999, p74), o Estado é constituído “por força e consenso, coerção e persuasão, Estado e Igreja, sociedade política e sociedade civil, política e moral, direito e liberdade, ordem e disciplina".

Inúmeras vezes esse conceito contribuiu para obscurecer o caráter contraditório das forças sociais que formavam a sociedade civil brasileira. Apesar dessa contraditoriedade, convergiam objetivamente na comum oposição à ditadura e resgatava o verdadeiro conceito sobre a sociedade civil, onde nem tudo o que faz parte da sociedade civil é bom e nem tudo o que provém do Estado é mau.

\section{CONCLUSÃO}

O objetivo desse estudo foi o de analisar teoricamente os desafios enfrentados nos pensamentos do filósofo italiano Antônio Gramsci, especificamente nos assuntos relativos à hegemonia, democracia, marxismo, lutas de classes e etc. Seus pensamentos têm como pano de fundo além da equidade social e a solidariedade baseando-se em um sistema dominante e 
produtivo cujo capital intelectual orgânico, ou não, se torna um dos pilares das atividades preponderantes da época. E de que época estamos nos referindo?

Tais reflexões apontam para uma atualidade impressionante que jamais se poderia prever que aconteceria por um olhar grande angular de semelhanças humanas e sociais sem a menor dicotomia entre ambas, onde se pode dizer que, a partir dessa época a humanização torna-se historicamente única.

Diante desses pensamentos de cunho teórico, pode-se afirmar que o homem não é naturalmente social, ele é historicamente social, podendo tornar-se um internacionalista, mas nunca deixando de ser um regionalista sendo considerado um construtor de nacionalidades lutando por seus direitos como por exemplo a luta entre a sociedade e as classes subalternas e tentando sempre entender conceitos e as relações que se estabelecem entre a classe e nação. Gramsci pode ser considerado se não o maior um dos maiores escritores contemporâneos que transitam por diversos assuntos sejam antigos ou ao mesmo tempo atuais, com propriedade.

Entende-se que a construção do futuro deve passar pelo passado e pelo presente na medida em que representa o reflexo de movimentos sociais locais, ou não, que se fortaleceram a partir da luta de classes.

Sendo assim, pode-se concluir que como em trabalhos acadêmicos baseados em pesquisa qualitativa, tal pesquisa apresentou uma visão ampla tentando a significação de uma aproximação da realidade passada com a atual. A perspectiva adotada pelo trabalho foi a de considerar um longo período de tempo, imprimindo uma apresentação com ampla descrição, explicações.

Difícil foi escrever esse final, onde a conclusão está longe, mas perto ficou a clareza com que muita coisa ficou a ser investigada. Por fim, espera-se que este estudo tenha contribuído para resgatar a memória de um grande homem, Antônio Gramsci, tão importante não só para a época de sua existência, mais que até hoje permanece em nossos pensamentos.

\section{REFERÊNCIAS}

BOBBIO, N. Ensaios sobre Gramsci e o conceito de sociedade civil. Rio de Janeiro:Paz e Terra. 1999.

COUTINHO, C. N. Gramsci. Um estudo sobre seu pensamento político. Nova edição ampliada. Rio de Janeiro, Civilização Brasileira, 1999.

DEL ROIO, M. (Organizador). Aspectos de Gramsci. Marília. Oficina Universitária Marília, 2009. 
DEL ROIO, M. Os prismas de Gramsci. A fórmula política da frente única (1919 - 1926). São Paulo, 2005.

FREIRE, P. Educação como prática da liberdade. São Paulo : Cortez. 1967.

Pedagogia do oprimido. Rio de Janeiro : Zahar. 1970.

GIL, A. C. Métodos e técnicas de pesquisa social. 4 ed. São Paulo: Atlas, 1994.

GRAMSCI, A. Caderno de Cárcere. R.J: Civilização Brasileira, 6v, 1999-2004.

MINAYO, M. C. de S. (Org.). Pesquisa social: teoria, método e criatividade. 8. ed. Petrópolis, RJ: Vozes, 1994.

MARCONI, M. A. LAKATOS, E. M. Fundamentos da Metodologia Científico. 5 edição. São Paulo. Atlas, 2003.

MARK, K e ENGELS, F. A ideologia alemã. São Paulo: Martins Fontes, 1998

SEMANARO, G. Gramsci e a sociedade civil. 2ª ed. Petrópolis : Vozes. 2001.

Gramsci e os novos embates da filosofia da práxis. Aparecida: Idéias e Letras. 2006.

SIMIONATTO I. Gramsci: sua teoria, incidência no Brasil, influência no Serviço Social.

Florianópolis, Editora da UFSC-Cortez. 1995. 